\title{
Habitat suitability and susceptibility modeling for strategic control of invasive Buffel grass, South Australia
}

\author{
Marshall, V., Ostendorf, B., Reynolds, T., Michaela, H., Tuke, J. and Lewis, M. \\ ${ }^{a}$ School of Earth and Environmental Sciences, The University of Adelaide \\ Email:Victoria.marshall@adelaide.edu.au
}

\begin{abstract}
Invasive plants are a major threat to environmental conservation and are costly to control. To effectively mitigate invasion natural resource managers need to anticipate potential damage, develop policies to prevent introduction as well as mitigate spread. Weed distribution modeling provides managers with the objective information required to strategically direct control efforts. However, often the empirical species distribution data needed to model habitat susceptibility to invasion are limited. For this reason, the benefits of mechanistic models (predictions based on knowledge of species environmental tolerances) are gaining recognition and acceptance. In a recent publication by Smith et al. (2012) a framework for estimating weed invasion potential that utilized expert knowledge of dispersal, establishment and persistence was presented. Here, we construct a model for the contentious weed species, Buffel grass in accordance with the theoretical framework proposed by Smith et al. (2012). This framework distinguishes between habitat suitability and susceptibility. In our study, maps for habitat suitability and susceptibility that incorporate both expert opinion and objective empirical modeling of 2010 Buffel grass roadside survey data are created. Presented are spatially explicit models of introduction pathways, habitat suitability and landscape susceptibility for Buffel grass invasion in the arid zone of South Australia. Results show the relative susceptibility of arid South Australia to Buffel grass invasion. The inclusion of empirical data in this modeling framework presented several challenges, such as the "persistence" indicator, which requires a time component, difficult to quantify empirically. The use of this theoretical framework for spatially explicit modeling requires more thought on how to tackle scale, particularly regarding how the scale of the expert observation lines up with the scale of available environmental data layers, and this is the focus of our discussion.
\end{abstract}

Keywords: Habitat suitability modeling, Cenchrus ciliaris, Pennisetum ciliare, weeds management 


\section{INTRODUCTION}

Invasive plants pose a serious threat to the environmental values of infested regions and can be costly to control. Approaches to invasive species management are moving increasingly towards spatial explicit predictive modeling of species potential distribution to prioritise mitigation efforts at regional scales. Buffel grass (Cenchrus ciliaris), an African perennial tussock, popular in arid rangeland worldwide, arguably signifies the greatest threat to biodiversity in arid environments. It's a threat primarily because of its impact on wildfire regimes which can create a positive feedback loop favoring Buffel grass regeneration. South Australian natural resource management regions are actively controlling Buffel grass infestations within their jurisdictions in accordance with the South Australian Buffel grass Strategic Plan 2012-2017 (Biosecurity SA 2012). In 2010 a comprehensive roadside survey was conducted in regional arid South Australia to map Buffel grass. This data has been used to construct empirical habitat suitability models (HSMs) for Buffel grass in arid South Australia (Marshall et al. 2013, Under revision).

There is the need for objective information to be used in risk assessment of invasive species to aid the decision-making process on where to invest limited resources in pursuit of weed control and biodiversity conservation. Empirical models (predictions based on real species presence-absence data) typically produce the most regionally accurate predictions. However, often comprehensive species distribution data is lacking. For this reason, the benefits of models based on expert knowledge of species environmental tolerance such as Bayesian Belief Networks are gaining recognition and acceptance (Ellis et al. 2006). In a recent publication by Smith et al. (2012) a framework using a Bayesian Belief Network (BBN) for estimating weeds invasion potential that utilized expert knowledge of dispersal establishment and persistence was presented. The framework makes a distinction between habitat suitability and susceptibility. Here, the HSM constructed by Marshall et al. (2013, Under revision) is adapted to allow spatially explicit predictions within the theoretical framework proposed by Smith et al. (2012). Key outputs of this paper are spatially explicit models of introduction pathways, habitat suitability and landscape susceptibility for Buffel grass invasion in the arid zone of South Australia based on objective, spatially explicit data collected within an area of approximately $25,000 \mathrm{~km}^{2}$.

\section{METHODS AND MATERIALS}

\subsection{Study Area}

The study is based in arid South Australia (Figure 1). Species occurrence data was obtained from 2010 Buffel grass Roadside Survey (Shepherd et al. 2010) that transverses approximately $550 \mathrm{~km}$ squared of arid SA (Figure 1); the spatially explicit habitat models derived from this data are produced for the full extent of the arid climatic region in South Australia. Elevation in this region ranges from below sea level within salt lakes, such as Lake Eyre, to over $1000 \mathrm{~m}$ in the Gammon and Flinders Ranges. Vegetation is predominantly low-lying chenopod shrubland, and stony plains, which allow clear views of the land adjacent the roadside. Vegetation on surrounding hills is typically open mallee woodland. The land is predominantly used for sheep and cattle grazing of natural vegetation; few differences can be observed in land cover as a result of management throughout the study area.
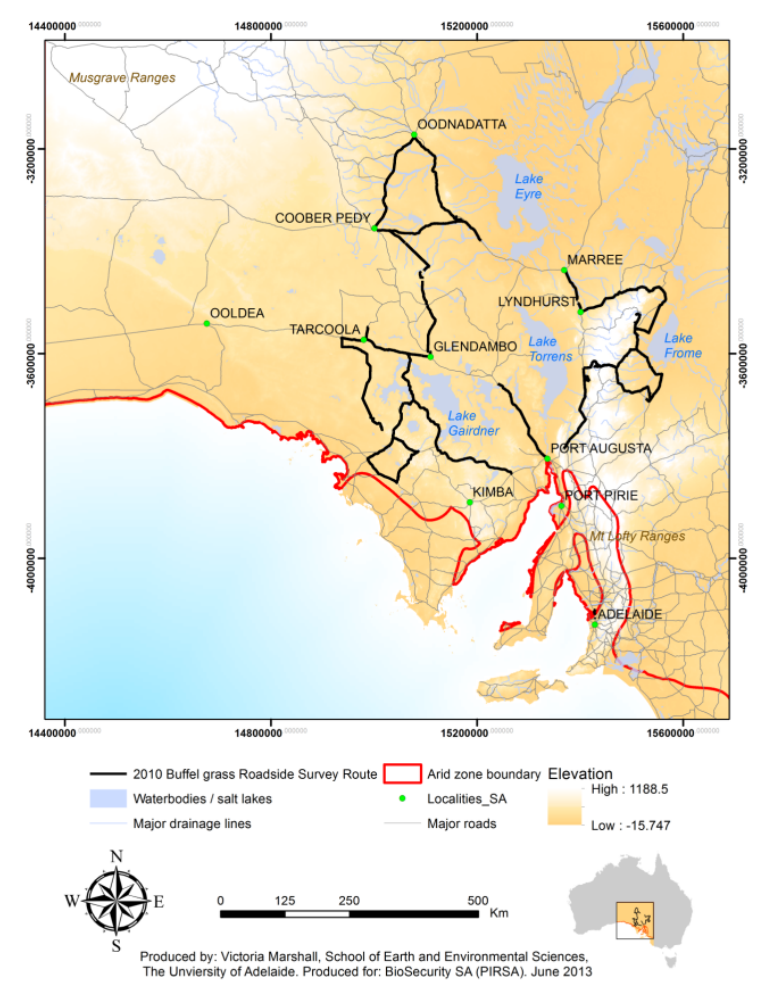

Figure 1: the 2010 Buffel grass Roadside Survey Route (black line) and the arid zone boundary (red line) used as predictive modeling extent for South Australia 


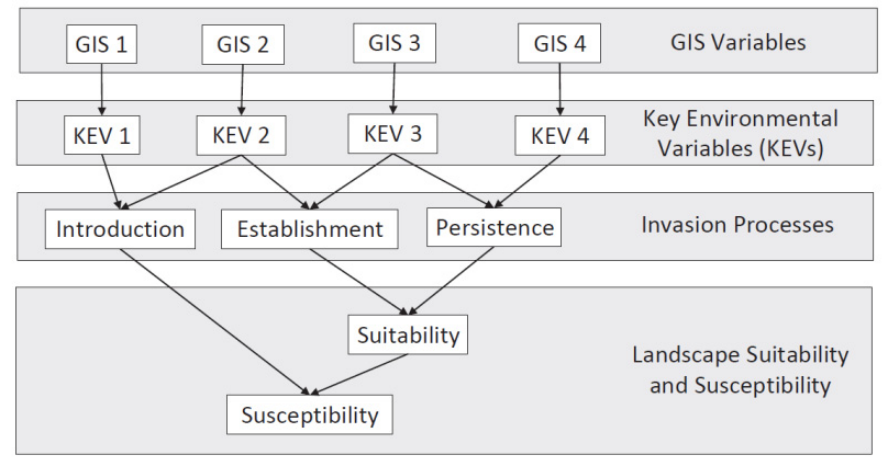

Figure 2: Theoretical framework for modeling landscape susceptibility to weed invasion (Smith et al. 2012)

\subsection{Theoretical framework for modeling landscape susceptibility to weed invasion}

The theoretical framework proposed by Smith et al (2012) is based on the three fundamental invasion processes common to all plants: introduction/ dispersal, establishment, and persistence at a site. Establishment and persistence determine a site's suitability for invasion, and this combined with introduction vectors and pathways determines the sites susceptibility to invasion (Figure 2). Unlike Smith et al (2012) who applies BBN (mechanistic) we utilize this theoretical framework to develop a hybrid empirical-mechanistic model. The construction of our hybrid framework for introduction pathways, habitat suitability and susceptibility is described below.

Introduction pathways were selected based on expert knowledge and we did not utilise any empirical data in our approach to modeling introduction pathways. The reason for this is that roads are a key vector for spread, but since our data is based on roadside survey, roads could not be included as a covariate in an empirical model. Instead, a geographic information system (GIS)-based model was constructed. Introduction pathways were identified as water courses, roads, especially major roads, townships, and railroads. The formula for weighting introduction risk was simple: The closer to an introduction pathway, the more likely introduction would occur. So "distance to" each of the introduction layers were calculated. Each "distance to" layer was normalised between 1 and 10 . Then the layers were added to represent the cumulative impact of having multiple introduction pathways at any given point. Note that, Buffel grass source populations were identified as an introduction factor but excluded from the model to preserve the models relevance over time.

Habitat suitability was modeled using an additive logistic regression analysis; selected environmental variables were regressed against Buffel grass presence-absence data obtained during 2010 Buffel grass Roadside Survey. This model represents habitat suitability for establishment only (persistence is excluded). Inclusion of "persistence" would require either a repeat survey or some surrogate measure of persistence such as patch size/ rate of spread or patch size $>10$ ha, in order to quantify persistence. For this reason, "persistence" was excluded from our adapted invasion risk framework.

In accordance with the theoretical framework, habitat susceptibility is the combined impact of introduction pathways and habitats suitability. We normalise between 1 and 10 both Introduction Pathways and the Habitat Suitability GIS layers then calculate the product (multiply the two GIS layers), to represent the interaction between suitability and introduction. The resulting map is a graduated map with values $1-100$ from low to high relative landscape susceptibility to invasion.

\subsection{Model inputs and construction}

\subsubsection{Overview}

This section describes the model inputs for each spatially explicit model of Buffel grass Invasion Pathways, Habitat Suitability and Habitat Susceptibility. An overview of out modeling framework and how the input variables fit together is depicted in Figure 3. This demonstrates the hybrid nature of our framework; it also provides a quick view of the key environmental variables used in our empirical habitat suitability model and the input variables used in our GIS-based introduction pathways model.

\subsubsection{Key Introduction Pathways (KIPs)}

The Introduction Pathways model was based on the natural log of "distance to" the following: drainage lines, all roads, major roads only (excluding minor roads), towns, and railroads. Source and specifications of KIPs are summarized in Table 1. To calculate a "Sum of Weights" score akin to "likelihood of introduction" each of the "distance to" layers was normalized from $1-10$. Normalized "distance to" layers were then added together in the GIS environment. 


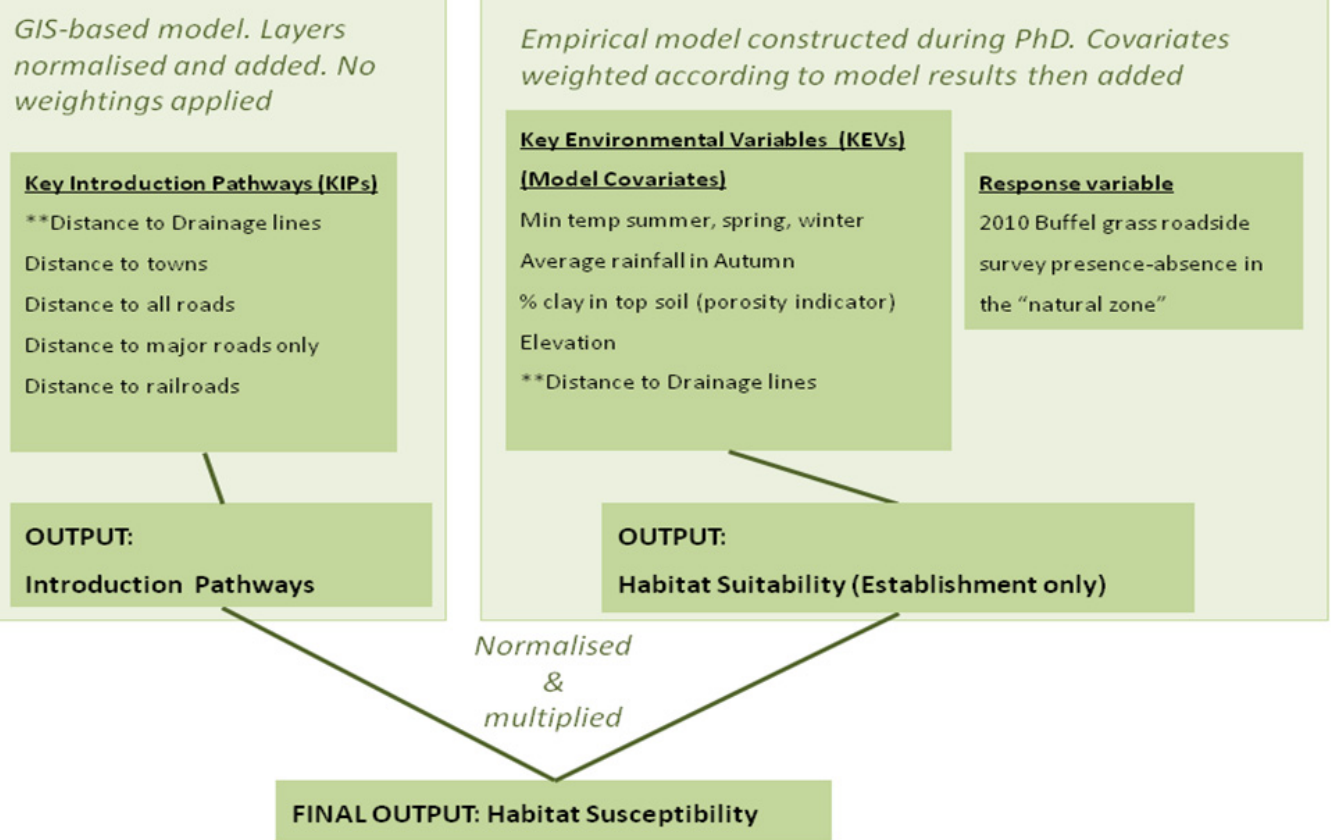

Figure 3 Theoretical framework adapted from Smith et al (2012) for modeling landscape susceptibility to Buffel grass invasion; input variables used for modeling habitat suitability and susceptibility also shown. $(* *)$ indicates variable duplication in Final Output.

Table 1 Source and specifications of key introduction pathways datasets used in GIS "sum of weights" model of Buffel grass Introduction Pathways

\begin{tabular}{ll}
$\begin{array}{l}\text { Key Introduction } \\
\text { Pathways }\end{array}$ & Details \\
\hline $\begin{array}{l}\text { Distance to water / drainage } \\
\text { lines }\end{array}$ & $\begin{array}{l}\text { Continuous; calculated from Water bodies and detailed drainage line data (cell size } \\
=25,25 \mathrm{~m}) ; \text { natural log transformed }\end{array}$ \\
\hline $\begin{array}{l}\text { Distance to all roads (major } \\
\text { and minor) }\end{array}$ & $\begin{array}{l}\text { Continuous; calculated from Detailed Road network polyline data (cell size }=50,50 \mathrm{~m} \text { ) } \\
\text {; natural log transformed }\end{array}$ \\
\hline Distance to towns & $\begin{array}{l}\text { Continuous; calculated from Localities dataset (includes major towns and regional } \\
\text { centres but does not include regional communities such as Oak Valley and Kalka) } \\
\text { (cell size }=100,100 \mathrm{~m}) ; \text { natural log transformed }\end{array}$ \\
\hline $\begin{array}{l}\text { Distance to major roads only } \\
\text { (excluding minor roads) }\end{array}$ & $\begin{array}{l}\text { Continuous; calculated from major Road network polyline data (cell size }=50,50 \mathrm{~m}) ; \\
\text { natural log transformed PIRSA }\end{array}$ \\
\hline Distance to Railroads & Continuous; calculated from major Road network polyline data (cell size $=500,500 \mathrm{~m})$ \\
& ; natural log transformed
\end{tabular}

\subsubsection{Buffel grass roadside survey: Response variable for habitat suitability modeling}

Roadside survey was carried out from 6th to 14th of May 2010 to map the regional distribution of Buffel grass in arid South Australia (Shepherd et al. 2010). There were two crucial elements of this survey which made the data usable in habitat suitability modeling: (1) the continuous collection of presence and absence data for the entire survey route and (2) the distinction (at the time of data collection) between roadside and adjacent land (Area beyond the roadside relatively unaffected by anthropogenic disturbances; the dynamic threshold separating roadside and adjacent land is defined in the Survey Report). This second feature is vital because the roadside is a biased environment that favors seedling establishment and is a pathway and vectorcarrier for the spread of Buffel grass. Full details of the roadside survey methodology (adapted from 2005 Buffel grass Roadside surveys conducted by Rural Solutions SA) can be found in (Shepherd et al. 2010); the benefit of making this roadside-adjacent land distinction is quantified in (Marshall et al. 2013, Under revision). Presence-absence on "Adjacent land" (referred to as "Natural Zone" in (Shepherd et al. 2010)) were used as the response variable in our habitat suitability model (HSM).

\subsubsection{Key Environmental Variables (KEVs)}

We initially considered approximately 50 environmental variables for inclusion in our Buffel grass habitat suitability model that can be broadly classified as climatic, geological/ landscape, anthropogenic and vegetation. Values at each survey data point were extracted from these environmental layers (Table 2) for further analysis and through a series of statistical test of independence and covariance we selected a subset of 
KEVs for inclusion in our model. The KEVs initially included in the model were: distance to drainage lines, vegetation (growth form in tallest and lowest stratum), elevation, temperature, rainfall, geology (stratigraphic description) and percentage of clay in the topsoil (an indicator of soil porosity). These were regressed against Buffel grass occurrence using the glm function ("stats" package, R) (R Development Core Team 2008). A stepwise / step down logistic regression analysis assessed based on the Akaike Information Criterion (AIC) was implemented using the step-AIC function (MASS package, R) (Venables et al. 2002). Ultimately, KEVs incorporated into the spatially explicit habitat suitability model for Buffel grass were: minimum temperature in spring, summer and winter, average rainfall in autumn, elevation, percentage of clay in the top soil, and vegetation growth form in the lower and upper stratum.

\section{Table 2 Source and specifications of environmental covariate datasets}

\begin{tabular}{|c|c|c|}
\hline KEVs & Details & Data Source \\
\hline $\begin{array}{l}\text { Climatic variables } \\
\text { (temperature, } \\
\text { rainfall, humidity) }\end{array}$ & $\begin{array}{l}\text { Continuous; monthly means based on standard 30-years } \\
\text { climatology (1961-1990); Humidity is as recorded at 9am. } \\
\text { Temperature and Rainfall are mean monthly minimum and } \\
\text { maximum; Seasonal averages calculated }\end{array}$ & Australian Bureau of Meteorology \\
\hline Surface geology & $\begin{array}{l}\text { Categorical; intended for use at scales between } 1: 5,000,000 \\
\text { and } 1: 2,500,000 \text {, compiled by different authors, } 2010 \text { edition }\end{array}$ & Geoscience Australia, ID: ANZCW0703013575 \\
\hline $\begin{array}{l}\text { Percentage of clay } \\
\text { in top soil }\end{array}$ & $\begin{array}{l}\text { Continuous; Surface of predicted \% Clay in soil layer } 1 \text { (A } \\
\text { Horizon - Top-soil) surface for the intensive agricultural areas } \\
\text { of Australia, derived from soil mapping by different agencies }\end{array}$ & $\begin{array}{l}\text { Australian Soil Resources Information System } \\
\text { (ASIRS) custodian - National Land and Water } \\
\text { Resources Audit (NLWRA) }\end{array}$ \\
\hline Elevation & $\begin{array}{l}\text { Continuous; 9-second }\left(\begin{array}{lll}250 & \mathrm{~m}\end{array}\right) \text { Digital Elevation Model } \\
\text { (DEM-9S, Version 3) }\end{array}$ & Geoscience Australia, ID: ANZCW0703011541 \\
\hline Vegetation & $\begin{array}{l}\text { Categorical; post-European settlement (1988), intended for use } \\
\text { at } 1: 5,000,000 \text { scales, areas over } 30,000 \text { hectares are shown; } \\
\text { attributes include type, growth form and dominant species in } \\
\text { upper and lower stratum }\end{array}$ & Geoscience Australia, ID: ANZCW0703005426 \\
\hline Land use & Categorical; generalised parcel-based land use & $\begin{array}{l}\text { Department of Planning, Transport and } \\
\text { Infrastructure, South Australia, Data set \# } 219\end{array}$ \\
\hline $\begin{array}{l}\text { Distance to water/ } \\
\text { drainage lines }\end{array}$ & $\begin{array}{l}\text { Continuous; calculated from Water bodies and detailed } \\
\text { drainage line data }(\text { cell size }=25,25 \mathrm{~m}) \text {; natural log }\end{array}$ & $\begin{array}{l}\text { Department of Primary Industries and Resources } \\
\text { of South Australia (PIRSA) }\end{array}$ \\
\hline
\end{tabular}

\section{RESULTS}

\subsection{Introduction Pathways}

The "Sum of Weights" executed in GIS environment to produce a spatially explicit introduction pathways map that shows the relative likelihood that Buffel grass could be introduced (Figure 4). The model indicates regions most prone to influx of Buffel grass seed are areas close to major roads, railroads, drainage lines and roads in general (major and minor). Regions where two or more of the model inputs intersect are more likely to see seed arrive, regional centers such as Port Augusta appear particularly prone to seed arrival.

\subsection{Habitat Suitability}

The statistical model (Table 3) was executed in GIS environment to produce a spatially explicit habitat suitability map (Figure 5). The model shows the relative suitability of the arid region of South Australia to support Buffel grass invasion. Environments highly suited to Buffel grass establishment occur in regions with dense drainage networks also in alignment with the Mt Lofty Ranges. Areas less suited to its establishment occur in the Victoria Desert and towards the South-East.

Table 3 Overall model performance of Buffel grass presence-absence model

\begin{tabular}{|c|c|c|c|c|}
\hline & & Coefficient & Probability & Significance \\
\hline & (Intercept) & -61.85000 & 0.00000 & $* * *$ \\
\hline \multirow[t]{5}{*}{ Vegetation } & Tallest stratum, growth form: Shrubs $>2 m$ & 4.20700 & 0.00010 & $* * *$ \\
\hline & Tallest stratum, growth form: Shrubs $<2 m$ & 4.10200 & 0.00018 & $* * *$ \\
\hline & Lowest stratum, growth form: Shrubs $>2 \mathrm{~m}$ & 4.34300 & 0.00174 & $* *$ \\
\hline & & Coefficient & Probability & Significance \\
\hline & Lowest stratum, growth form: Shrubs $<2 m$ & 5.60000 & 0.00000 & $* * *$ \\
\hline \multirow[t]{4}{*}{ Climate } & Rainfall (autumn) & 0.62340 & 0.00000 & $* * *$ \\
\hline & Minimum temperature (Summer) & 4.53500 & 0.00000 & $* * *$ \\
\hline & Minimum temperature (Spring) & -4.10800 & 0.00005 & $* * *$ \\
\hline & Minimum temperatures (Winter) & 2.11200 & 0.00187 & $* *$ \\
\hline \multirow[t]{3}{*}{ Landscape } & Percentage of clay in top soil (Porosity indicator) & -0.00004 & 0.06908 & . \\
\hline & Distance to water courses (natural log) & -0.43630 & 0.00000 & $* * *$ \\
\hline & Elevation & -0.00869 & 0.00527 & $* *$ \\
\hline
\end{tabular}




\subsection{Habitat Susceptibility}

The product of Introduction pathways (Figure 4) and Habitat Suitability (Figure 5) executed in a GIS environment produced a spatially explicit habitat susceptibility map that shows the landscape's relative susceptibility to Buffel grass invasion (Figure 6). Intuitively, the product shows that regions where high suitability coincides with high level of introduction pathways will be most susceptible to invasion.

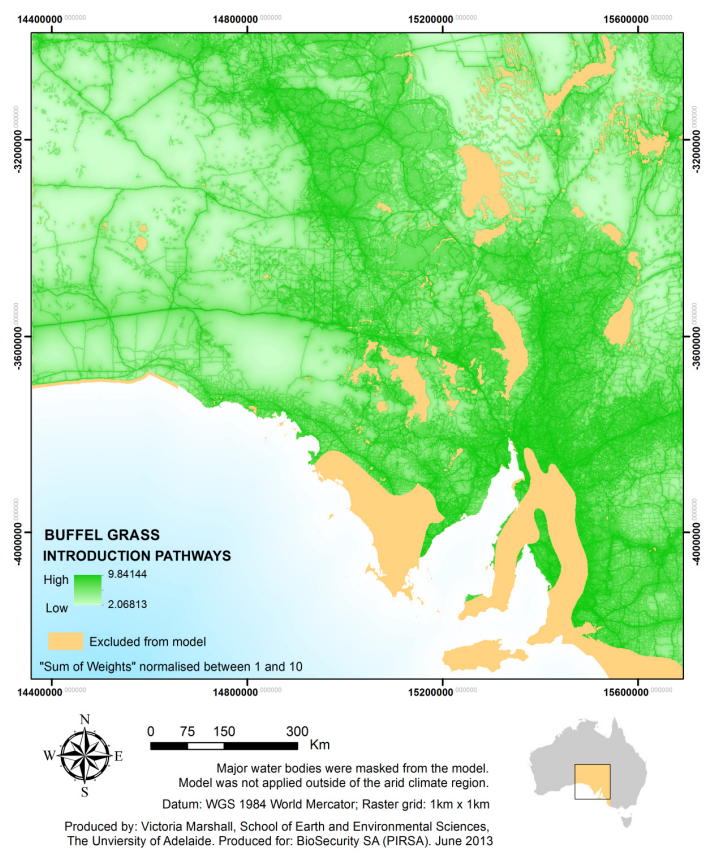

Figure 4 Buffel grass introduction pathways; "Sum of weights" normalised from 1 (low) to 10 (high) representing relative likelihood that Buffel grass could be introduced

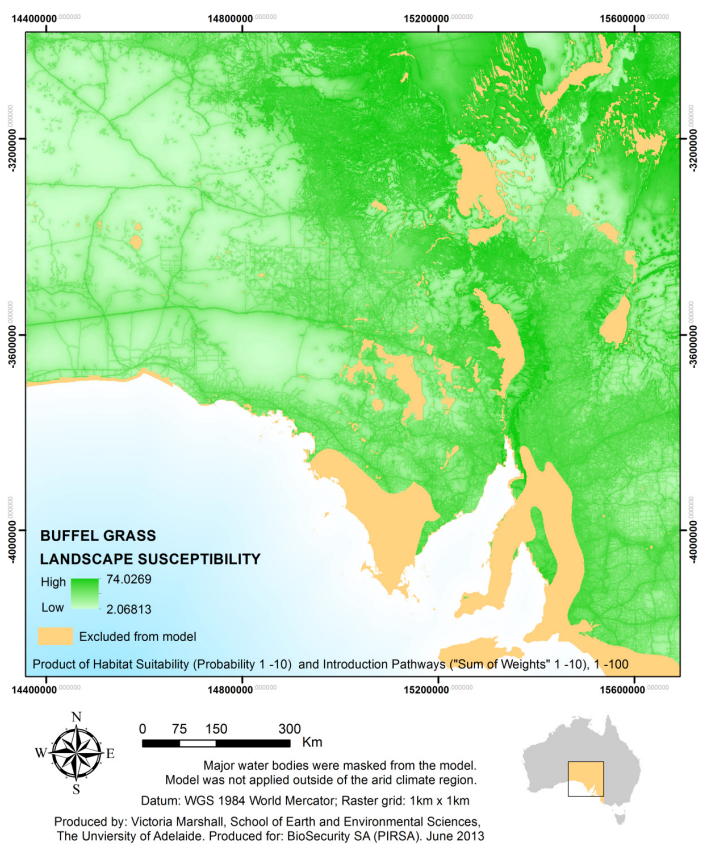

Figure 6 Buffel grass landscape susceptibility "Sum of weights" normalized from 1 (low) to 10 (high) representing relative likelihood that the landscape would be susceptible to Buffel grass invasion

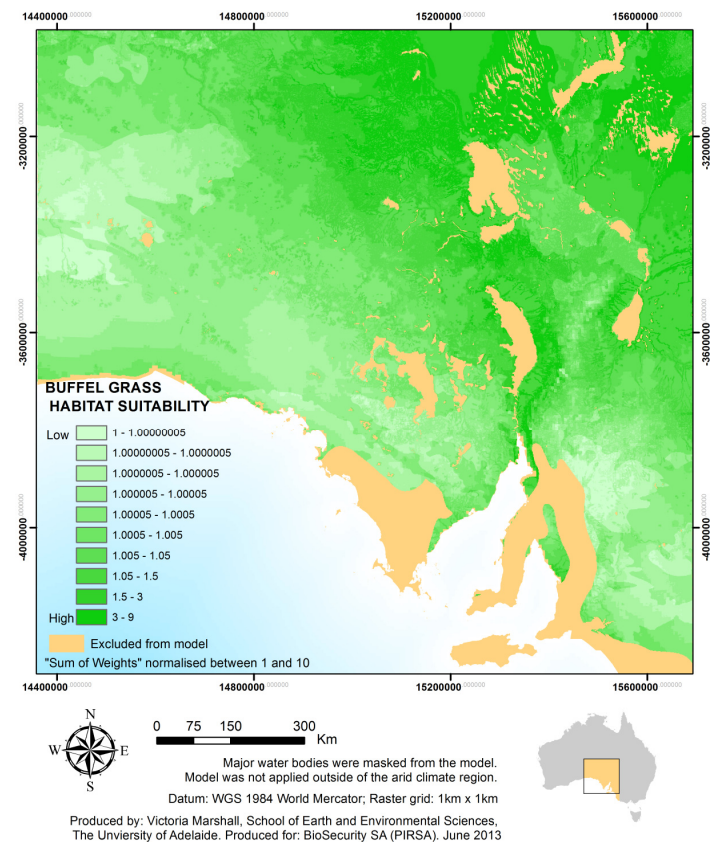

Figure 5 Buffel grass habitat suitability normalised from 1 (low) to 10 (high) representing relative likelihood that Buffel grass could establish

\section{DISCUSSION}

The theoretical framework presents a useful structure upon which to consider the three fundamental elements of invasion process (introduction, establishment and persistence). However, the segregation of these three processes presents challenges for spatially portraying the end product (the habitat/ landscape susceptibility model). The first challenge which presents is that a vector for spread (and therefore an Introduction input variable) could also be a determinant of establishment and persistence. Specifically, we encounter this issue with Key Environmental Variable (KEV), "Distance to Drainage lines and water bodies". Buffel grass is known to be dispersed along waterways, but also disturbance caused by water and the increased soil moisture, make waterways particularly suited for Buffel grass establishment. In this scenario, we chose to incorporate it in both "introduction" and 
"suitability" models, thus it is weighted more strongly in the final model, which is realistic.

The next major challenge is that of scale and this is not made plain in the suggested framework. Ecological processes operate at different scales. In this example, we identified five introduction pathways: all linear features in the landscape, which become challenging to interpret at a state-wide scale. The state-wide habitat suitability depicted at 1:1000km scale, is not an acceptable resolution for Introduction pathways, typically in this case less than $50 \mathrm{~m}$ wide. This issue is partially addressed by using "distance to" as the measurable input. However, this presents an ecological question of how far can seed disperse? Should there be a distance limit, where it is completely unlikely that the seed could spread from that pathway? Perhaps pathways should be considered at an alternative scale to that of suitability. An additional consideration of scale, although not relevant in this study, is how to capture and document expert observations and opinions which are likely formed at a localised scale, and may not be applicable at state wide scales, which due to limitations of data availability and resolution they are likely to be.

The framework presented is intended for construction of mechanistic models. Here, we attempted to hybridise the model, to include some empirical data. The modeling research that underpins this study and is presented in (Marshall et al. 2013, Under revision) was constructed using all the KEVs listed for this study, as well as, introduction factors "distance to towns" and "roadside occurrence" ("roadside" populations recorded on 2010 Buffel grass roadside survey). In order to fit the Theoretical Framework for modeling invasion, empirical modeling was rerun for this study to exclude those introduction pathways. How this change alters the statistical prediction is untested. It may or may not be comparable. However, it is worth noting that there is difference and the overall impact of utilising this framework on the performance of spatially explicit models should be explored more thoroughly prior to adopting this framework for empiricalhybridised models in future.

\section{CONCLUSIONS}

This report delivers three spatially explicit models of introduction pathways, habitat suitability and landscape susceptibility to Buffel grass invasion. The models are best viewed interactively in a GIS environment as regional detail is lost at the state wide scale. Drainage lines appear most susceptible to invasion, and areas where roads intersect drainage lines should be monitored closely. Overall accuracy of the models is yet to be tested. The theoretical framework proposed by Smith et al. (2012) represents a useful structure upon which to model landscape susceptibility, and although intended for mechanistic modeling, functioned for the hybrid empirical model presented here. For future application of this framework it will be useful to develop protocol for spatially referencing expert opinion and handling of duplicate input variables across the three invasion phases.

\section{REFERENCES}

Biosecurity SA (2012). South Australian Buffel grass Strategic Plan 2012-2017: A plan to reduce the weed threat of buffel grass in South Australia. G. o. S. Australia.

Ellis, R., Marcot, G., and McCann, R.K. (2006) "Bayesian belief networks: applications in ecology and natural resource management" Canadian Journal of Forest Resaerch 36 (12)

Marshall, V. M., Lewis, M. M., Ostendorf, B. and Tuke, J. (2013, Under revision). "Buffel grass (Cenchrus ciliaris) roadside survey and invasive species distribution modelling " Environmental Monitoring and Assessment

R Development Core Team (2008). R: A language and environment for statistical computing. Vienna, Austria, R Foundation for Statistical Computing.

Shepherd, B. and Marshall, V. M. (2010). Roadside Buffel grass survey report Adelaide, Australia, Rural Solutions Department of Water Land and Biodiversity.

Smith, C., van Klinken, R. D., Seabrook, L. and McAlpine, C. (2012). "Estimating the influence of land management change on weed invasion potential using expert knowledge." Diversity and Distributions 18(8): 818-831.

Venables, W. N. and Ripley, B. D. (2002). Modern Applied Statistics with S. New York, Springer. 